\title{
Shield Optimization and Formulation of Regression Equations for Split-Ring Resonator
}

\author{
Tahir Ejaz, Hamood Ur Rahman, T. Tauqeer, Adnan Masood, and Tahir Zaidi
}

National University of Sciences and Technology (NUST), Islamabad 44000, Pakistan

Correspondence should be addressed to Tahir Ejaz; tahir.ejaz@ceme.nust.edu.pk

Received 24 October 2015; Accepted 20 December 2015

Academic Editor: Zhike Peng

Copyright ( 2016 Tahir Ejaz et al. This is an open access article distributed under the Creative Commons Attribution License, which permits unrestricted use, distribution, and reproduction in any medium, provided the original work is properly cited.

\begin{abstract}
Microwave resonators are widely used for numerous applications including communication, biomedical and chemical applications, material testing, and food grading. Split-ring resonators in both planar and nonplanar forms are a simple structure which has been in use for several decades. This type of resonator is characterized with low cost, ease of fabrication, moderate quality factor, low external noise interference, high stability, and so forth. Due to these attractive features and ease in handling, nonplanar form of structure has been utilized for material characterization in 1-5 GHz range. Resonant frequency and quality factor are two important parameters for determination of material properties utilizing perturbation theory. Shield made of conducting material is utilized to enclose split-ring resonator which enhances quality factor. This work presents a novel technique to develop shield around a predesigned nonplanar split-ring resonator to yield optimized quality factor. Based on this technique and statistical analysis regression equations have also been formulated for resonant frequency and quality factor which is a major outcome of this work. These equations quantify dependence of output parameters on various factors of shield made of different materials. Such analysis is instrumental in development of devices/designs where improved/optimum result is required.
\end{abstract}

\section{Introduction}

Split-ring resonator (SRR) [1], loop-gap resonator (LGR) [2-4], or open-loop resonator (OLR) [5] is an important component which is utilized in electronic and nonelectronic applications/utilities. These include devices like oscillators, filters, tuned amplifiers, frequency meters, and processes like permittivity measurement, compositional analysis, quality control, and so forth. SRR is characterized with low phase noise, moderate quality $(Q)$ factor, low cost, and ease of fabrication. Material characterization and compositional analysis especially for polar liquids in microfluidic channels $[6,7]$ have also been performed with the help of this structure in 1-5 $\mathrm{GHz}$ range.

Compositional analysis for determining volume fraction of dielectric materials in a compound/composite is often performed in biomedical, chemical, pharmaceutical, and petrochemical applications, food processing/grading, forensic testing, and other applications/areas. Classical methods are time consuming and often require expensive equipment, and above all different methods have to be adopted for various materials. It has been shown that microwave method using split-ring resonator can be used for highly sensitive compositional analysis $[6,7]$ for various materials. In this technique material under test (MUT) is placed inside SRR in a region of maximum electric field strength. When volume fraction of materials in MUT is changed complex permittivity of composite changes. Variation in complex permittivity of MUT is sensed through changes in resonant frequency and $Q$ factor. Due to placement of MUT in region of maximum electric field very small changes in composite composition have been detected [6]. The larger the change in these parameters for small compositional variation the higher the sensitivity of device and hence the higher the resolution in analysis. Key to enhancing sensitivity and resolution in analysis through this technique is the optimization of $Q$ factor pertaining to SRR structure.

SRR is enclosed inside a conducting cylindrical shield/ cavity to prevent radiation loss and enhance $Q$ factor $[1,8]$. Resonant frequency, $Q$ factor, and other parameters are 


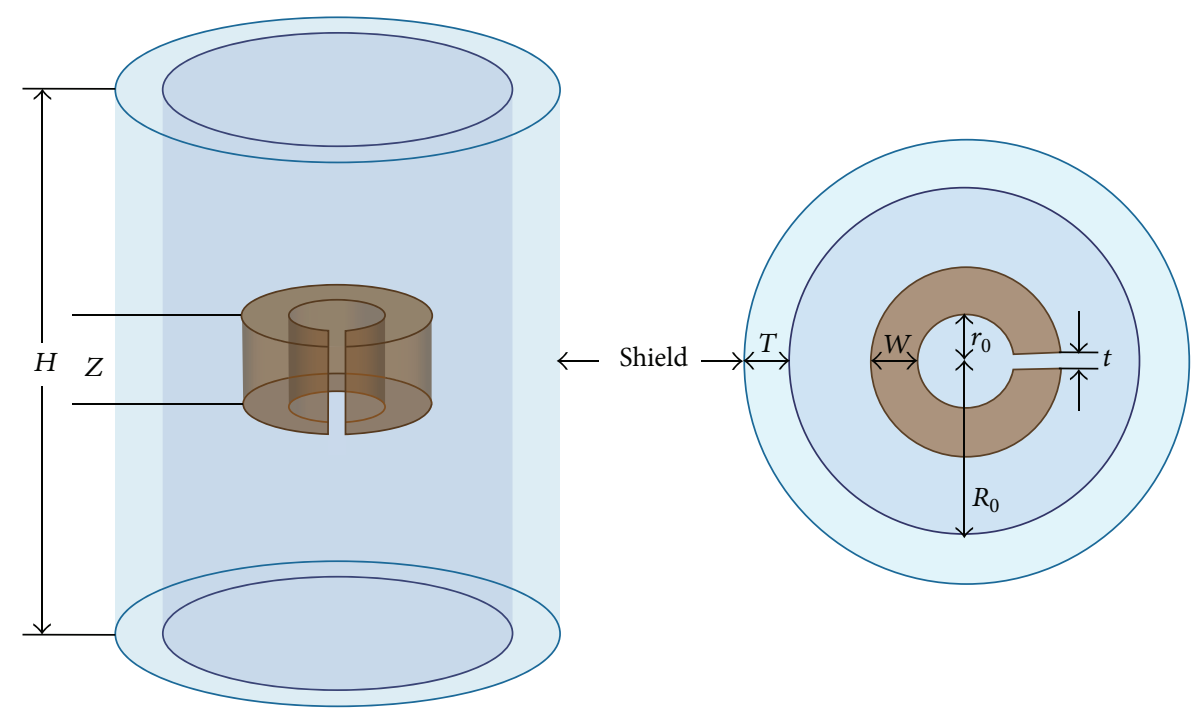

FIGURE 1: Split-ring resonator structure and its cross-sectional view.

affected by shield dimensions and material characteristics like conductivity, dielectric constant, mass density, and dielectric loss [9]. Various models [1-4, 10-12] have been developed to quantize output parameters of SRR structure. Subsequent analyses $[13,14]$ of these models highlight a number of shield parameters which include material and dimensions which can be utilized to develop a structural design to optimize $Q$ factor. This work focuses on analyzing effects of these parameters of shield on resonant frequency and $Q$ factor of SRR structure. Analysis of these effects was used to design shield around SRR to yield optimized $Q$ factor $[15,16]$. Regression equations were also formulated through statistical analysis to determine dependence of resonant frequency and $Q$ factor on shield parameters. Such analysis is instrumental in the development of an optimized SRR structure/device for performing highly sensitive compositional analysis of dielectric materials in a mixture/composite.

\section{SRR Structure for Analysis}

A simplest form of SRR structure with resonator enclosed in conducting cylindrical shield is shown in Figure $1[3,4]$. It is comprised of a metallic cylinder with a longitudinal gap. SRR can have a number of variations including planar forms $[5$, 17], geometrical shapes [17, 18], multiple rings [18], and multiple gaps [10]. It can be considered as a single-turn inductor connected with a gap capacitor [5] as shown in the figure. SRR has to be coupled with transmission line and needs mechanical support [10]. Inductive, capacitive, or aperture/hole coupling [19] of SRR can be done based on its utilization.

Earlier research $[6,7,11,20]$ provided guidance in formulation of a base design. Gap was selected to accommodate microfluidic channel [7]. Guidelines have been provided for selecting various shield design parameters [3, 4]. SRR was fabricated using copper [6]. Design parameters of SRR structure are shown in Table 1.
TABle 1: Parameters of base design.

\begin{tabular}{lc}
\hline Design parameters & Dimensions $(\mathrm{mm})$ \\
\hline Inner radius of shield " $R_{0}$ " & 24 \\
Inner radius of resonator " $r_{0}$ " & 6 \\
Width of resonator " $W$ " & 6 \\
Length of resonator " $Z$ " & 6 \\
Gap of resonator " $t$ " & 2 \\
Inner height of shield " $H$ " & 24 \\
Thickness of shield " $T$ " (in all directions) & 4 \\
\hline
\end{tabular}

TABle 2: Properties of shield material.

\begin{tabular}{lccc}
\hline $\begin{array}{l}\text { Shield } \\
\text { material }\end{array}$ & $\begin{array}{c}\text { Relative } \\
\text { permeability } \\
\mu_{r}\end{array}$ & $\begin{array}{c}\text { Bulk } \\
\text { conductivity } \\
\sigma, \text { Siemens }\end{array}$ & $\begin{array}{c}\text { Mass density } \\
\rho, \mathrm{kg} / \mathrm{m}^{3}\end{array}$ \\
\hline AL & 1.000021 & 38000000 & 2689 \\
BR & 1 & 15000000 & 8600 \\
SS & 1 & 1100000 & 8055 \\
CI & 60 & 1500000 & 7200 \\
SN & 1 & 8670000 & 7304 \\
\hline
\end{tabular}

\section{Simulation}

3.1. Effect of Shield Material. Simulations were performed to analyze shield material effect on resonant frequency and $Q$ factor of base design. Shield was designed using aluminum $(\mathrm{AL})$, brass (BR) [6], stainless steel (SS), cast iron (CI), and tin (SN). Some useful properties of these materials are shown in Table 2. Parametric results are presented in Table 3. Developed structure of SRR enclosed in shield is shown in Figure 2.

Figure 3 shows variations in output parameters of SRR with shields of different materials. SRR structures with AL and CI shields have shown maximum and minimum resonant frequency, respectively. A mean value of $2.1026 \mathrm{GHz}$ with 
TABLE 3: Simulated parametric results.

\begin{tabular}{lcc}
\hline Shield material & $\begin{array}{c}\text { Resonant frequency } \\
f_{0}[\mathrm{GHz}]\end{array}$ & Q factor \\
\hline $\mathrm{AL}$ & 2.10280 & 2406.20 \\
$\mathrm{BR}$ & 2.10278 & 2338.35 \\
$\mathrm{SS}$ & 2.10269 & 1942.16 \\
$\mathrm{CI}$ & 2.10198 & 846.31 \\
$\mathrm{SN}$ & 2.10277 & 2283.73 \\
\hline
\end{tabular}

$0.000351 \mathrm{GHz}$ as standard deviation was achieved. Maximum variation in resonant frequency for SRR shield made of different material is 0.039 percent. This suggests that resonant frequency is independent of shield material. In this case, resonant frequency is a function of SRR and shield dimensions but is independent of shield material properties. However, Q factor is considerably affected with change in shield material. Maximum value for SRR structure with AL shield was achieved while minimum value with CI shield was achieved. Mean value is 1963 with 650 as standard deviation. Moreover, maximum variation is 64.83 percent which is quite large. This suggests that variation is due to material properties/characteristics mentioned in Table $2[1,3,4]$.

Further statistical analysis was carried out utilizing design of experiment (DOE) method [21-23] with data as given in Table 4 . The table has been formed by combining material properties of Table 2 and parametric output data of Table 3. The table forms basis for analyzing effects of material properties on resonant frequency and quality factor. Regression analysis [22, 23] was performed which yielded results for resonant frequency and $Q$ factor as shown in Tables 5 and 6, respectively. Regression equations $[22,23]$ were obtained for full factorial DOE. Equations show effects of shield material properties on resonant frequency and $Q$ factor as

$$
\begin{aligned}
f_{0}= & 2.103-0.000013 \times \mu_{r}-0.000000 \times \sigma-0.000000 \\
& \times \rho+0.000000 \times \sigma \times \rho \\
Q= & 3664.00-21.7100 \times \mu_{r}-0.000042 \times \sigma-0.21540 \\
& \times \rho+0.000000 \times \sigma \times \rho .
\end{aligned}
$$

These equations also verify earlier investigations [2-4]. It can be noted that resonant frequency decreases negligibly with increase in relative permeability of shield material while it remained unaffected by bulk conductivity and mass density of shield material. Moreover, $Q$ factor decreases considerably with increase in relative permeability; however it slightly decreases with increase in mass density and bulk conductivity. It remained unaffected against bulk conductivity and mass density of resonator material. Analysis show that $Q$ factor can be optimized by selecting a shield material for which relative permeability is low enough along with appropriate bulk conductivity and mass density.

3.2. Materialwise Effect of Height and Thickness of Shield. For analyzing effects on resonant frequency and $Q$ factor against variation in shield dimensions, five simulations one for each

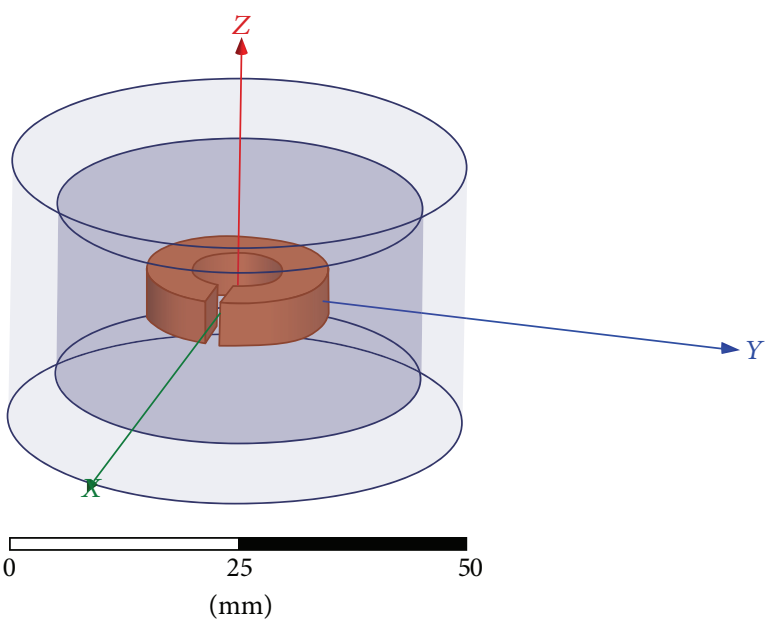

FIGURE 2: HFSS simulation of SRR.

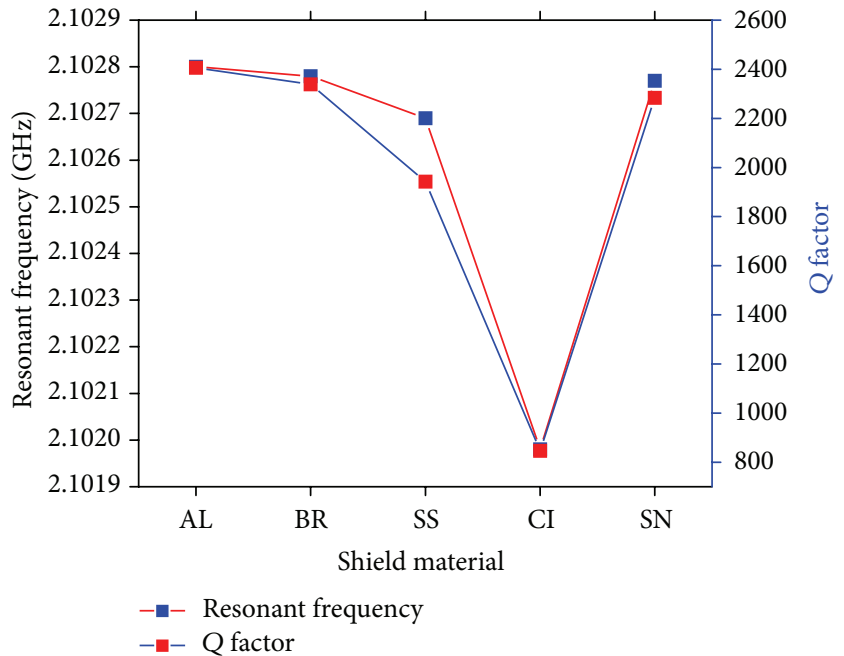

FIGURE 3: Parametric variations due to shield material.

shield material were designed. Inner radius of shield was kept as value given in Table 1 . Range of parametric variations introduced is shown in Table 7. Height of shield has seven levels while wall thickness has five levels. Each simulation resulted in thirty-five solutions. Results of these simulations for SRR with AL shield are presented in Figure 4.

Figure 4(a) presents effect on resonant frequency against shield height for various thicknesses pertaining to AL shield whereas Figure 4(b) presents effect on $Q$ factor for the same variations. Figures $4(\mathrm{c})$ and $4(\mathrm{~d})$ depict parametric variations but plotted against shield thickness for various shield heights. Resonant frequency was highest for a $25 \mathrm{~mm}$ high and $5 \mathrm{~mm}$ thick wall shield, whereas the lowest value was yielded for shield dimensions of $25 \mathrm{~mm}$ high and $7 \mathrm{~mm}$ wall thickness. Highest $Q$ factor was observed with $25 \mathrm{~mm}$ high and $5 \mathrm{~mm}$ thick shield, whereas the lowest value was achieved for $24 \mathrm{~mm}$ high and $8 \mathrm{~mm}$ thick wall shield.

Effects on resonant frequency and $Q$ factor due to variations in height and wall thickness of shield pertaining to other materials were studied in a similar manner. Extreme values of resonant frequency and $Q$ factor along with related shield 
TABLE 4: Statistical analysis: shield material.

\begin{tabular}{|c|c|c|c|c|c|}
\hline Shield material & $\begin{array}{l}\text { Relative permeability } \\
\mu_{r}\end{array}$ & $\begin{array}{l}\text { Bulk conductivity } \sigma \text {, } \\
\text { Siemens }\end{array}$ & $\begin{array}{c}\text { Mass density } \\
\rho, \mathrm{kg} / \mathrm{m}^{3}\end{array}$ & $\begin{array}{l}\text { Resonant frequency } \\
(\mathrm{GHz})\end{array}$ & $Q$ factor \\
\hline $\mathrm{AL}$ & 1.000021 & 38000000 & 2689 & 2.10280 & 2406.20 \\
\hline $\mathrm{BR}$ & 1 & 15000000 & 8600 & 2.10278 & 2338.35 \\
\hline SS & 1 & 1100000 & 8055 & 2.10269 & 1942.16 \\
\hline $\mathrm{CI}$ & 60 & 1500000 & 7200 & 2.10198 & 846.31 \\
\hline SN & 1 & 8670000 & 7304 & 2.10277 & 2283.73 \\
\hline
\end{tabular}

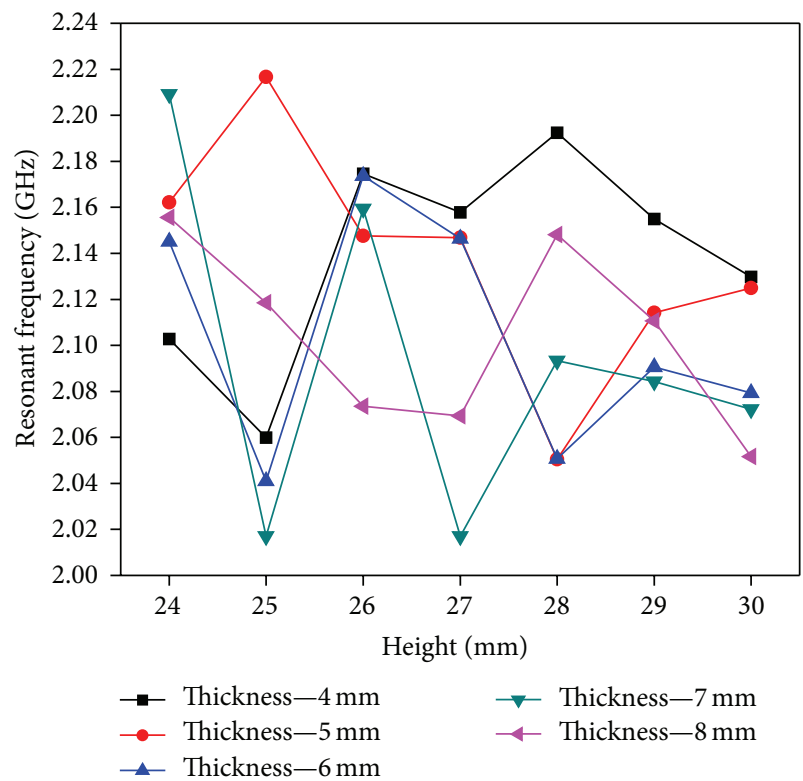

(a) Resonant frequency versus height of shield

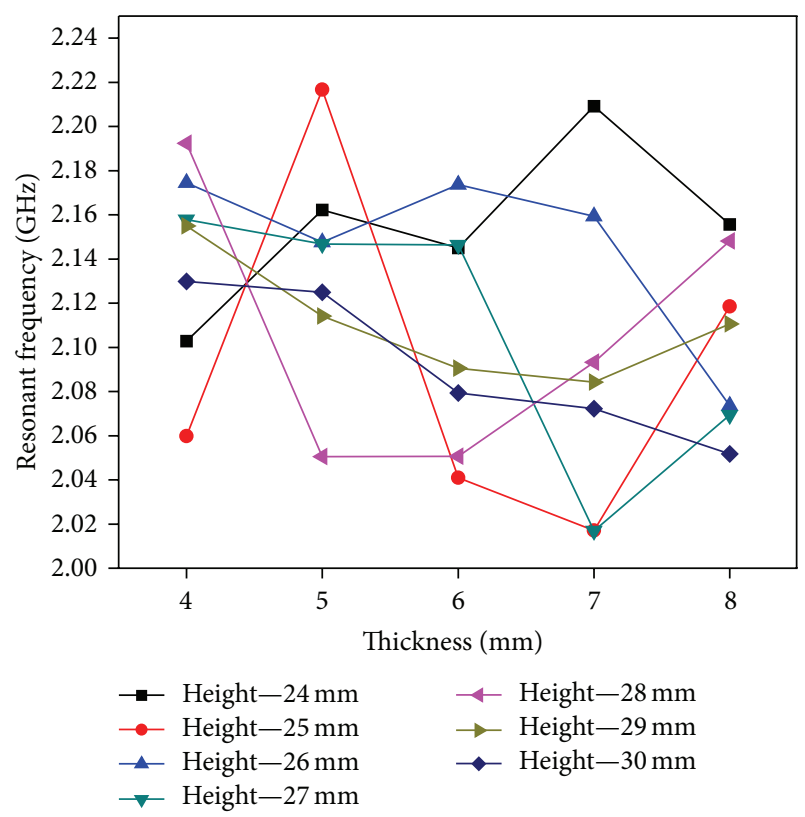

(c) Resonant frequency versus thickness of shield

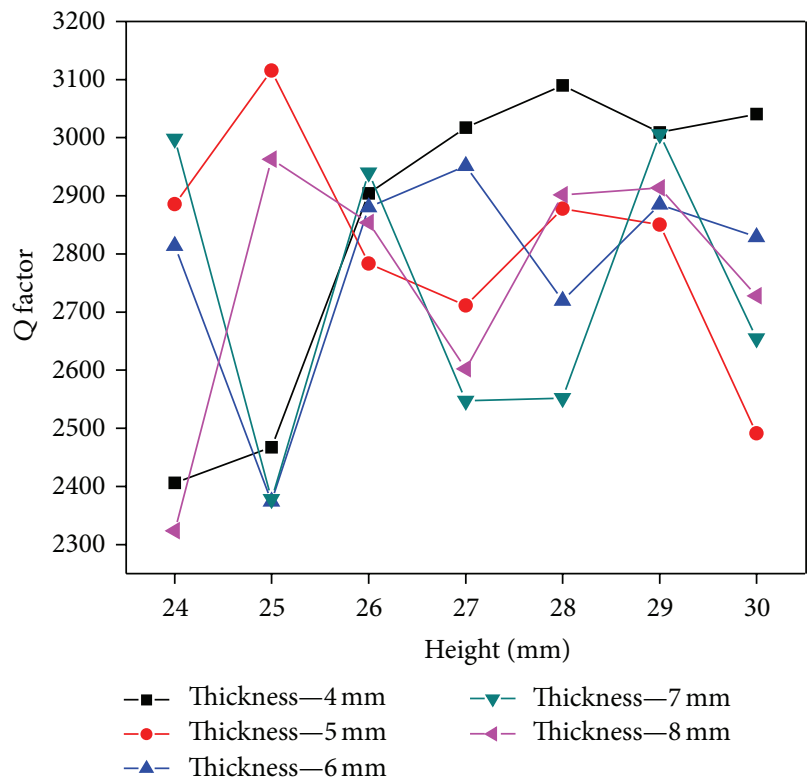

(b) $Q$ factor versus height of shield

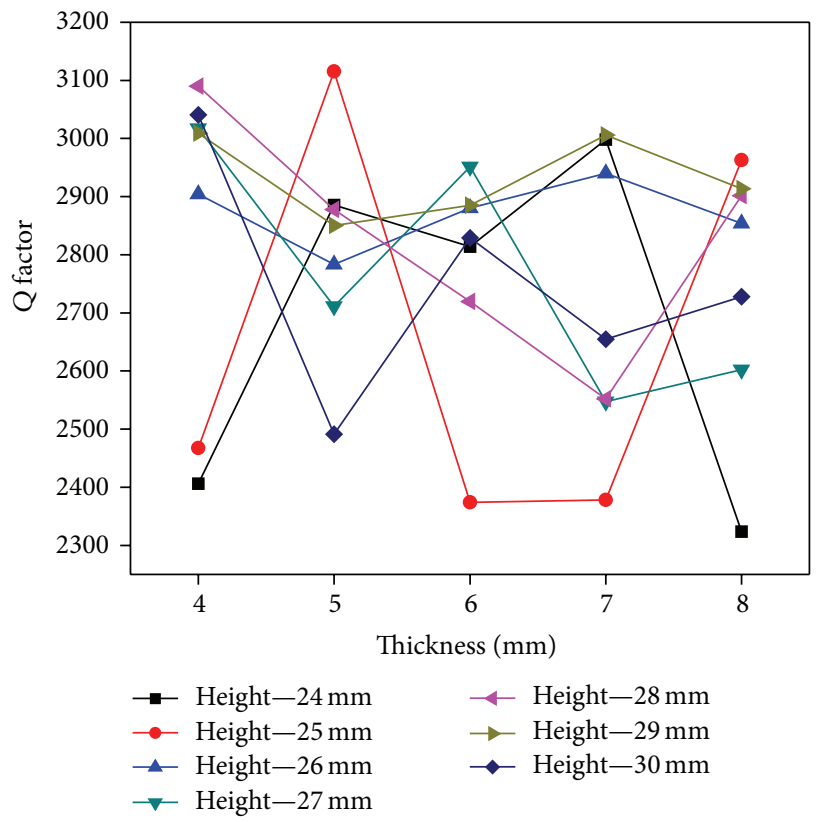

(d) $Q$ factor versus thickness of shield

FIgURE 4: Parametric variations due to AL shield. 
TABLE 5: Regression analysis: resonant frequency.

\begin{tabular}{lccccc}
\hline Factors & DF & SS & MS = SS/DF & $F$-value & $P$ value \\
\hline Regression & 3 & 0.000000 & 0.000000 & 98.22 & 0.074 \\
$\mu_{r}$ & 1 & 0.000000 & 0.000000 & 150.48 & 0.052 \\
$\sigma$ & 1 & 0.000000 & 0.000000 & 1.97 & 0.394 \\
$\rho$ & 1 & 0.000000 & 0.000000 & 0.56 & 0.592 \\
Error, $E$ & 1 & 0.000000 & 0.000000 & & \\
\hline Total & 4 & 0.000000 & & &
\end{tabular}

DF: degree of freedom, SS: sum of squares, and MS: mean square.

TABLE 6: Regression analysis: $Q$ factor.

\begin{tabular}{lccccc}
\hline Factors & DF & SS & MS = SS/DF & $F$-value & $P$ value \\
\hline Regression & 3 & 1657382 & 552461 & 18.28 & 0.170 \\
$\mu_{r}$ & 1 & 631835 & 631835 & 20.90 & 0.137 \\
$\sigma$ & 1 & 64150 & 64150 & 2.12 & 0.383 \\
$\rho$ & 1 & 20117 & 20117 & 0.67 & 0.564 \\
Error, $E$ & 1 & 30229 & 30229 & & \\
\hline Total & 4 & 1687612 & & & \\
\hline
\end{tabular}

TABLE 7: Range of parametric variations.

\begin{tabular}{lccc}
\hline Parameters & $\begin{array}{c}\text { Minimum } \\
(\mathrm{mm})\end{array}$ & $\begin{array}{c}\text { Range of variation } \\
\text { Maximum } \\
(\mathrm{mm})\end{array}$ & $\begin{array}{c}\text { Increment } \\
(\mathrm{mm})\end{array}$ \\
\hline Height " $H$ " & 24 & 30 & 1 \\
Thickness " $T$ " & 4 & 8 & 1 \\
\hline
\end{tabular}

dimensions pertaining to different materials are summarized in Table 8.

Parametric outputs achieved for statistical analysis for SRR structure with AL shield are given in Table 9. Statistical analysis data reveals mean value of $2.1155 \mathrm{GHz}$ for resonant frequency with $0.0531 \mathrm{GHz}$ as standard deviation. Maximum variation in resonant frequency for different shield dimensions is 7.92 percent. $Q$ factor has a mean value of 2784.8 with standard deviation of 223.3 whereas 63.99 percent was maximum variation observed. Regression analysis $[22,23]$ for resonant frequency and $Q$ factor on its dependencies upon dimensions of AL shield are given in Tables 10 and 11, respectively, whereas main effects' plot for resonant frequency and $Q$ factor is shown in Figure 5.

Two-level factorial regression equations were derived for full factorial DOE [23]. Equations for resonant frequency and $Q$ factor pertaining to SRR structure with AL shield are given as

$$
\begin{aligned}
f_{0}= & 1.780+0.0150 \times H+0.0862 \times T-0.00361 \times H \\
& \times T \\
Q= & 799+79.7 \times H+220 \times T-9.2 \times H \times T,
\end{aligned}
$$

where resonant frequency is in GHz. Similar data as shown in Table 9 was achieved for analysis of SRRs enclosed in shields

\begin{tabular}{|c|c|c|c|c|}
\hline \multirow{2}{*}{$\begin{array}{l}\text { Shield } \\
\text { material }\end{array}$} & \multicolumn{2}{|c|}{ Parametric output } & \multicolumn{2}{|c|}{ Shield dimensions $(\mathrm{mm})$} \\
\hline & & & Height & Thickness \\
\hline \multirow{4}{*}{$\mathrm{AL}$} & $f_{0}(\max )(\mathrm{GHz})$ & 2.2167 & 25 & 5 \\
\hline & $f_{0}(\min )(\mathrm{GHz})$ & 2.0410 & 25 & 6 \\
\hline & $Q$ factor $(\max )$ & 3115.55 & 25 & 5 \\
\hline & $Q$ factor $(\mathrm{min})$ & 2323.86 & 24 & 8 \\
\hline \multirow{4}{*}{$\mathrm{BR}$} & $f_{0}(\max )(\mathrm{GHz})$ & 2.2167 & 25 & 5 \\
\hline & $f_{0}(\min )(\mathrm{GHz})$ & 2.0170 & 25 & 7 \\
\hline & $Q$ factor $(\max )$ & 3019.78 & 25 & 5 \\
\hline & $Q$ factor $(\mathrm{min})$ & 2260.69 & 24 & 8 \\
\hline \multirow{4}{*}{ SS } & $f_{0}(\max )(\mathrm{GHz})$ & 2.2090 & 24 & 7 \\
\hline & $f_{0}(\min )(\mathrm{GHz})$ & 2.0142 & 26 & 4 \\
\hline & $Q$ factor $(\max )$ & 2573.31 & 30 & 4 \\
\hline & $Q$ factor (min) & 1889.18 & 24 & 8 \\
\hline \multirow{4}{*}{ CI } & $f_{0}(\max )(\mathrm{GHz})$ & 2.2083 & 24 & 7 \\
\hline & $f_{0}(\min )(\mathrm{GHz})$ & 2.0136 & 25 & 7 \\
\hline & $Q$ factor $(\max )$ & 1230.26 & 30 & 4 \\
\hline & $Q$ factor (min) & 836.70 & 24 & 8 \\
\hline \multirow{4}{*}{ SN } & $f_{0}(\max )(\mathrm{GHz})$ & 2.2022 & 24 & 7 \\
\hline & $f_{0}(\min )(\mathrm{GHz})$ & 2.0169 & 27 & 7 \\
\hline & $Q$ factor $(\max )$ & 2951.80 & 28 & 4 \\
\hline & $Q$ factor $(\min )$ & 2209.26 & 24 & 8 \\
\hline
\end{tabular}
of other materials. Regression analysis was carried out similar
TABLE 8: Extreme values related to shield dimensions.

to the one shown for AL shield in Tables 10 and 11. Twolevel factorial regression equations for full factorial DOE were generated [23] for each structure and given below.

Regression equations for SRR structure with BR shield are

$$
\begin{aligned}
f_{0}= & 1.956+0.0076 \times H+0.0660 \times T-0.00274 \times H \\
& \times T \\
Q= & 1527+45.8 \times H+112 \times T-4.5 \times H \times T .
\end{aligned}
$$

Regression equations for SRR structure with SS shield are

$$
\begin{aligned}
f_{0}= & 1.637+0.0182 \times H+0.1073 \times T-0.00411 \times H \\
& \times T \\
Q= & 75+82.7 \times H+160 \times T-6.07 \times H \times T .
\end{aligned}
$$

Regression equations for SRR structure with CI shield are

$$
\begin{aligned}
f_{0}= & 1.721+0.0149 \times H+0.0951 \times T-0.00362 \times H \\
& \times T \\
Q= & -431+56.4 \times H+21.4 \times T-0.91 \times H \times T .
\end{aligned}
$$

Regression equations for SRR structure with SN shield are

$$
\begin{aligned}
f_{0}= & 1.762+0.0156 \times H+0.0944 \times T-0.00390 \times H \\
& \times T \\
Q= & 434+87.7 \times H+243 \times T-9.9 \times H \times T .
\end{aligned}
$$


TABLE 9: Statistical analysis for SRR structure with AL shield.

\begin{tabular}{|c|c|c|c|}
\hline $\begin{array}{l}\begin{array}{l}\text { Height } \\
(\mathrm{mm})\end{array} \\
\end{array}$ & $\begin{array}{c}\text { Thickness } \\
(\mathrm{mm})\end{array}$ & Resonant frequency $(\mathrm{GHz})$ & $Q$ factor \\
\hline 24 & 4 & 2.102801 & 2406.20 \\
\hline 24 & 5 & 2.162182 & 2885.54 \\
\hline 24 & 6 & 2.145050 & 2814.10 \\
\hline 24 & 7 & 2.209145 & 2998.04 \\
\hline 24 & 8 & 2.155604 & 2323.86 \\
\hline 25 & 4 & 2.059838 & 2467.30 \\
\hline 25 & 5 & 2.216705 & 3115.55 \\
\hline 25 & 6 & 2.041012 & 2374.01 \\
\hline 25 & 7 & 2.017052 & 2377.98 \\
\hline 25 & 8 & 2.118541 & 2962.74 \\
\hline 26 & 4 & 2.174556 & 2904.15 \\
\hline 26 & 5 & 2.147571 & 2783.36 \\
\hline 26 & 6 & 2.173646 & 2880.35 \\
\hline 26 & 7 & 2.159383 & 2940.05 \\
\hline 26 & 8 & 2.073591 & 2853.99 \\
\hline 27 & 4 & 2.157872 & 3017.62 \\
\hline 27 & 5 & 2.146808 & 2711.32 \\
\hline 27 & 6 & 2.146426 & 2951.71 \\
\hline 27 & 7 & 2.016988 & 2547.46 \\
\hline 27 & 8 & 2.069348 & 2602.48 \\
\hline 28 & 4 & 2.192393 & 3089.93 \\
\hline 28 & 5 & 2.050508 & 2877.79 \\
\hline 28 & 6 & 2.050680 & 2719.64 \\
\hline 28 & 7 & 2.093319 & 2552.03 \\
\hline 28 & 8 & 2.148180 & 2901.54 \\
\hline 29 & 4 & 2.154959 & 3008.97 \\
\hline 29 & 5 & 2.114135 & 2850.55 \\
\hline 29 & 6 & 2.090548 & 2884.91 \\
\hline 29 & 7 & 2.084256 & 3006.12 \\
\hline 29 & 8 & 2.110622 & 2913.54 \\
\hline 30 & 4 & 2.129782 & 3040.76 \\
\hline 30 & 5 & 2.124868 & 2491.20 \\
\hline 30 & 6 & 2.079355 & 2829.28 \\
\hline 30 & 7 & 2.072270 & 2654.94 \\
\hline 30 & 8 & 2.051706 & 2727.87 \\
\hline
\end{tabular}

From (2)-(6) resonant frequency and $Q$ factors can be predicted for each category of structure with predesigned SRR. It can be observed that resonant frequency was slightly affected due to change in height and thickness of shield whereas $Q$ factor was considerably affected due to dimensional changes in shield as already shown in Table 8.

3.3. Materialwise Effect of Height, Radius, and Thickness of Shield. Inner radius of shield was kept constant in Section 3.2
TABLE 10: Regression analysis: resonant frequency.

\begin{tabular}{lccccc}
\hline Factors & DF & SS & MS = SS/DF & $F$-value & $P$ value \\
\hline Regression & 2 & 0.015463 & 0.007731 & 3.07 & 0.060 \\
Height & 1 & 0.006329 & 0.006329 & 2.52 & 0.122 \\
Thickness & 1 & 0.009133 & 0.009133 & 3.63 & 0.066 \\
Error, $E$ & 32 & 0.080482 & 0.002515 & & \\
\hline Total & 34 & 0.095944 & & & \\
\hline
\end{tabular}

TABLE 11: Regression analysis: $Q$ factor.

\begin{tabular}{lccccc}
\hline Factors & DF & SS & MS = SS/DF & $F$-value & $P$ value \\
\hline Regression & 2 & 139132 & 69566 & 1.43 & 0.254 \\
Height & 1 & 85561 & 85561 & 1.76 & 0.194 \\
Thickness & 1 & 53570 & 53570 & 1.10 & 0.302 \\
Error, $E$ & 32 & 1556319 & 48635 & & \\
\hline Total & 34 & 1695450 & & & \\
\hline
\end{tabular}

TABLE 12: Range of parametric variations.

\begin{tabular}{lccc}
\hline Parameters & $\begin{array}{c}\text { Minimum } \\
(\mathrm{mm})\end{array}$ & $\begin{array}{c}\text { Range of variation } \\
\text { Maximum } \\
(\mathrm{mm})\end{array}$ & $\begin{array}{c}\text { Increment } \\
(\mathrm{mm})\end{array}$ \\
\hline Height & 24 & 30 & 1 \\
Radius & 22 & 30 & 1 \\
Thickness & 4 & 8 & 1 \\
\hline
\end{tabular}

to analyze effects separately. Another set of analysis was designed for SRR structures with shield of different materials to analyze effects on resonant frequency and $Q$ factor against additional dimension, that is, shield radius. Each analysis was designed to have three hundred fifteen solutions due to additional nine levels of shield radius. Range of parametric variations introduced in this analysis is given in Table 12.

Results of SRR structure with shield of different materials were obtained in a manner described in previous section. Data pertaining to these simulations were used for statistical analysis. Extreme values of parametric output with related shield dimensions are presented in Table 13.

Maximum resonant frequency for all SRR structures was found almost equal. Interestingly, this value was obtained for the same shield dimensions. This observation also showed that resonant frequency remains unaffected by shield material. Similar observation was made for minimum value of resonant frequency and maximum value of $Q$ factor except for structure with CI shield. Minimum $Q$ factor was obtained for the same shield dimensions made of AL and BR. Highest $Q$ factor was noted for structure with AL shield. An improvement of around 26 percent in $Q$ factor was noted from original design along with slight increase in resonant frequency. Regression analysis for resonant frequency and $Q$ factor was performed for full factorial DOE to analyze dependence of these factors on shield dimensions as shown in Tables 14 and 15, respectively, whereas main effects' plot for resonant frequency and $Q$ factor is shown in Figure 6. 


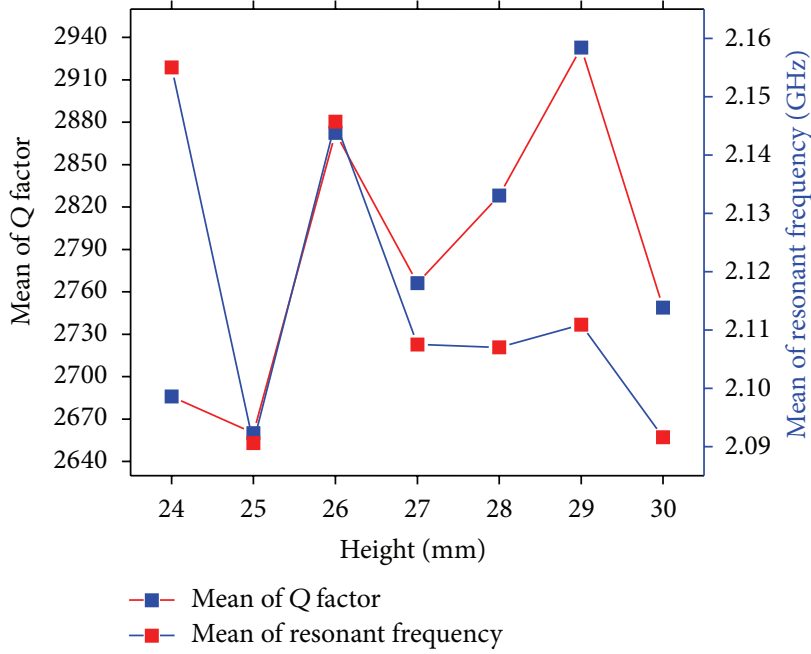

(a) Mean of $Q$ factor and resonant frequency versus height of shield

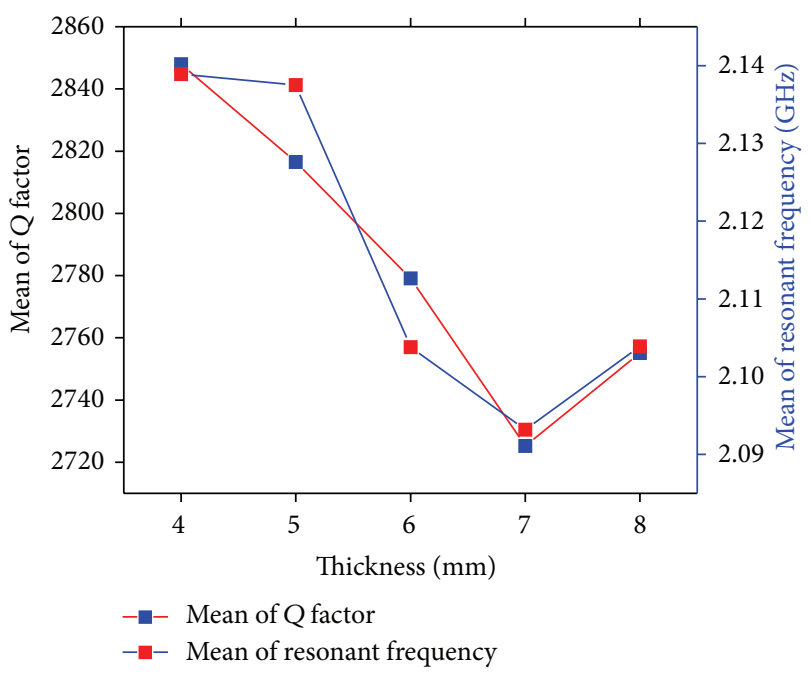

(b) Mean of $Q$ factor and resonant frequency versus thickness of shield

FIGURE 5: Main effects plot: resonant frequency and $Q$ factor-AL shield.

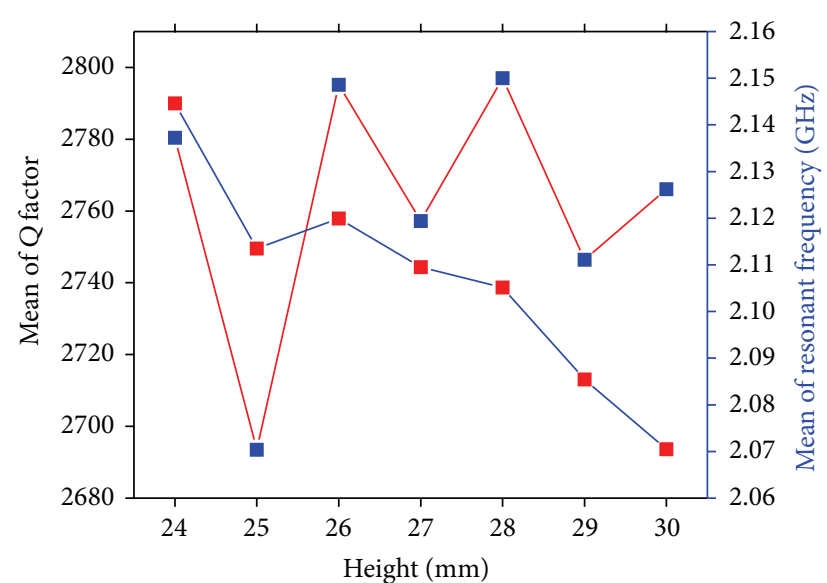

- Mean of $Q$ factor

- - Mean of resonant frequency

(a) Mean of $Q$ factor and resonant frequency versus height of shield

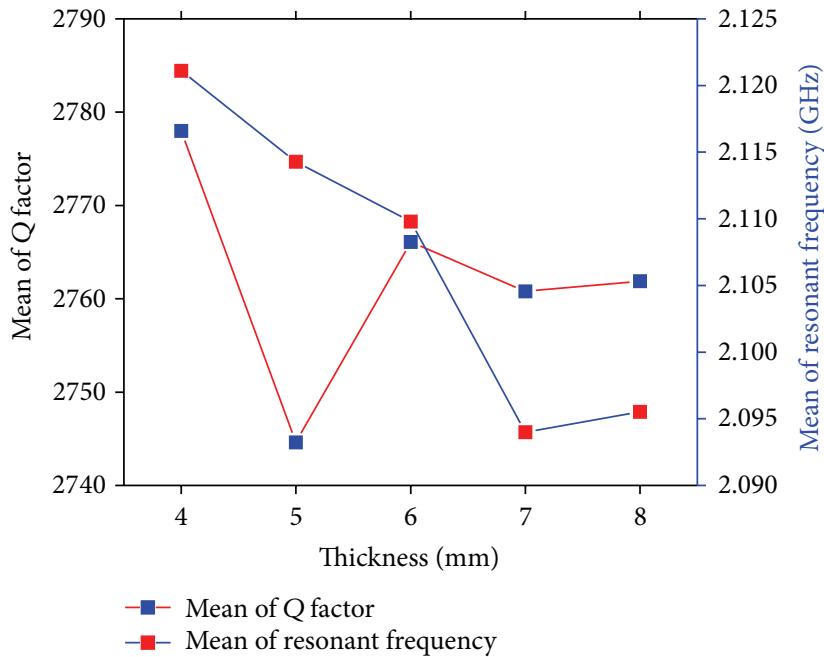

(b) Mean of $Q$ factor and resonant frequency versus thickness of shield

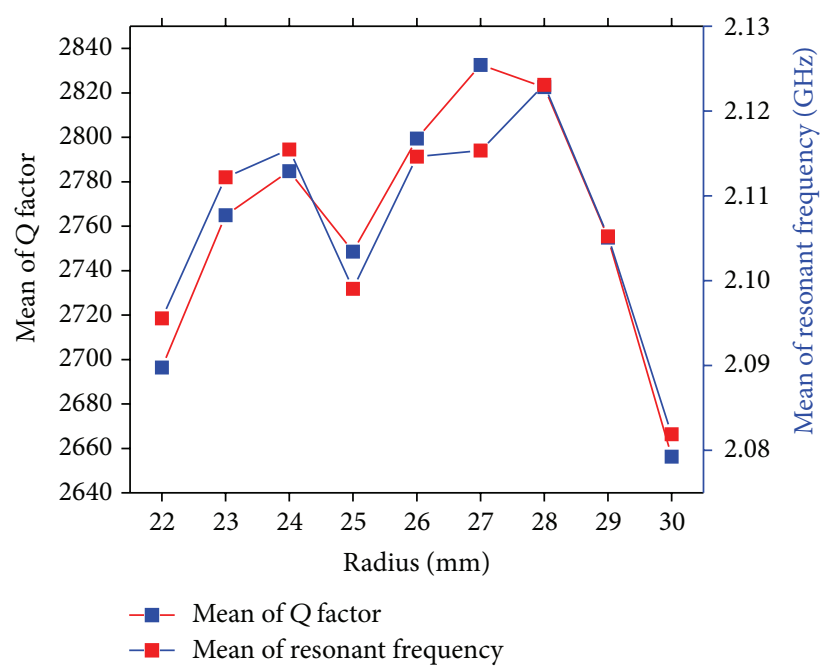

(c) Mean of $Q$ factor and resonant frequency versus radius of shield

FIGURE 6: Main effects plot: resonant frequency and $Q$ factor-AL shield. 
TABLE 13: Extreme values related to shield dimensions.

\begin{tabular}{|c|c|c|c|c|c|}
\hline \multirow{2}{*}{$\begin{array}{l}\text { Shield } \\
\text { material }\end{array}$} & \multirow{2}{*}{\multicolumn{2}{|c|}{ Parametric output }} & \multicolumn{3}{|c|}{ Shield dimensions (mm) } \\
\hline & & & Height & Radius & Thickness \\
\hline \multirow{4}{*}{$\mathrm{AL}$} & $f_{0}(\max )(\mathrm{GHz})$ & 2.2184 & 24 & 23 & 4 \\
\hline & $f_{0}(\min )(\mathrm{GHz})$ & 1.9322 & 29 & 30 & 5 \\
\hline & $Q$ factor $(\max )$ & 3226.05 & 28 & 27 & 4 \\
\hline & $Q$ factor (min) & 2129.90 & 29 & 30 & 4 \\
\hline \multirow{4}{*}{ BR } & $f_{0}(\max )(\mathrm{GHz})$ & 2.2184 & 24 & 23 & 4 \\
\hline & $f_{0}(\min )(\mathrm{GHz})$ & 1.9322 & 29 & 30 & 5 \\
\hline & $Q$ factor (max) & 3151.12 & 28 & 27 & 4 \\
\hline & $Q$ factor $(\min )$ & 2100.71 & 29 & 30 & 4 \\
\hline \multirow{4}{*}{ SS } & $f_{0}(\max )(\mathrm{GHz})$ & 2.2183 & 24 & 23 & 4 \\
\hline & $f_{0}(\min )(\mathrm{GHz})$ & 1.9322 & 29 & 30 & 5 \\
\hline & $Q$ factor $(\max )$ & 2697.54 & 28 & 27 & 4 \\
\hline & $Q$ factor $(\mathrm{min})$ & 1799.00 & 24 & 29 & 5 \\
\hline \multirow{4}{*}{ CI } & $f_{0}(\max )(\mathrm{GHz})$ & 2.2176 & 24 & 23 & 4 \\
\hline & $f_{0}(\min )(\mathrm{GHz})$ & 1.7938 & 30 & 29 & 4 \\
\hline & $Q$ factor (max) & 1388.51 & 30 & 29 & 5 \\
\hline & $Q$ factor (min) & 830.21 & 24 & 23 & 5 \\
\hline \multirow{4}{*}{ SN } & $f_{0}(\max )(\mathrm{GHz})$ & 2.2184 & 24 & 23 & 4 \\
\hline & $f_{0}(\min )(\mathrm{GHz})$ & 1.9322 & 29 & 30 & 5 \\
\hline & $Q$ factor $(\max )$ & 3090.23 & 28 & 27 & 4 \\
\hline & $Q$ factor (min) & 2066.21 & 27 & 22 & 7 \\
\hline
\end{tabular}

TABLE 14: Regression analysis: resonant frequency.

\begin{tabular}{lccccc}
\hline Factors & DF & SS & MS = SS/DF & $F$-value & $P$ value \\
\hline Regression & 3 & 0.17150 & 0.057167 & 19.21 & 0.000 \\
Height & 1 & 0.13821 & 0.138208 & 46.45 & 0.000 \\
Radius & 1 & 0.00113 & 0.001125 & 0.38 & 0.539 \\
Thickness & 1 & 0.03217 & 0.032166 & 10.81 & 0.001 \\
Error, $E$ & 311 & 0.92527 & 0.002975 & & \\
\hline Total & 314 & 1.09677 & & & \\
\hline
\end{tabular}

Two-level factorial regression equations were derived for full factorial DOE [23]. Equations obtained for resonant frequency and $Q$ factor of AL shield are given as

$$
\begin{aligned}
f_{0}= & -0.22+0.0996 \times H+0.0909 \times R_{0}+0.469 \times T \\
& -0.00383 \times H \times R_{0}-0.0195 \times H \times T \\
& -0.0165 \times R_{0} \times T+0.000683 \times H \times R_{0} \times T \\
Q= & -7677+421 \times H+333 \times R_{0}+1866 \times T-13.6 \\
& \times H \times R_{0}-74.8 \times H \times T-60.8 \times R_{0} \times T \\
& +2.47 \times H \times R_{0} \times T .
\end{aligned}
$$

Regression analysis for SRRs enclosed in shields made of other materials was carried out. Two-level factorial regression equations for full factorial DOE were generated for each structure and are given below.
TABLE 15: Regression analysis: $Q$ factor.

\begin{tabular}{lccccc}
\hline Factors & DF & SS & MS = SS/DF & $F$-value & $P$ value \\
\hline Regression & 3 & 8852 & 2950.5 & 0.06 & 0.981 \\
Height & 1 & 6674 & 6674.5 & 0.14 & 0.713 \\
Radius & 1 & 562 & 561.8 & 0.01 & 0.915 \\
Thickness & 1 & 1615 & 1615.3 & 0.03 & 0.857 \\
Error, $E$ & 311 & 15358691 & 49384.9 & & \\
\hline Total & 314 & 15367542 & & & \\
\hline
\end{tabular}

Regression equations for SRR structure with BR shield are

$$
\begin{aligned}
f_{0}= & 0.25+0.0829 \times H+0.0705 \times R_{0}+0.403 \times T \\
& -0.00309 \times H \times R_{0}-0.0171 \times H \times T \\
& -0.0134 \times R_{0} \times T+0.000571 \times H \times R_{0} \times T \\
Q= & -6215+363 \times H+265 \times R_{0}+1626 \times T-11.1 \\
& \times H \times R_{0}-65.7 \times H \times T-50.6 \times R_{0} \times T \\
& +2.08 \times H \times R_{0} \times T .
\end{aligned}
$$

Regression equations for SRR structure with SS shield are

$$
\begin{aligned}
f_{0}= & 0.85+0.0597 \times H+0.0460 \times R_{0}+0.341 \times T \\
& -0.00217 \times H \times R_{0}-0.0146 \times H \times T \\
& -0.0109 \times R_{0} \times T+0.000473 \times H \times R_{0} \times T \\
Q= & -3448+227 \times H+134 \times R_{0}+1086 \times T-5.5 \\
& \times H \times R_{0}-43.9 \times H \times T-32.8 \times R_{0} \times T \\
& +1.36 \times H \times R_{0} \times T .
\end{aligned}
$$

Regression equations for SRR structure with CI shield are

$$
\begin{aligned}
f_{0}= & 0.62+0.0767 \times H+0.0655 \times R_{0}+0.364 \times T \\
& -0.00325 \times H \times R_{0}-0.0167 \times H \times T \\
& -0.0135 \times R_{0} \times T+0.000619 \times H \times R_{0} \times T \\
Q= & -18+34.3 \times H-19.4 \times R_{0}+283 \times T+0.99 \\
& \times H \times R_{0}-12.0 \times H \times T-9.5 \times R_{0} \times T \\
& +0.410 \times H \times R_{0} \times T .
\end{aligned}
$$

Regression equations for SRR structure with SN shield are

$$
\begin{aligned}
f_{0}= & 0.34+0.0810 \times H+0.0655 \times R_{0}+0.394 \times T \\
& -0.00325 \times H \times R_{0}-0.0170 \times H \times T \\
& -0.0131 \times R_{0} \times T+0.000567 \times H \times R_{0} \times T \\
Q= & -6613+377 \times H-276 \times R_{0}+1613 \times T-11.5 \\
& \times H \times R_{0}-65.7 \times H \times T-50.4 \times R_{0} \times T \\
& +2.10 \times H \times R_{0} \times T .
\end{aligned}
$$


Equations (7)-(11) present dependence of output parameters on shield dimensions. Values of resonant frequency and $Q$ factor can be predicted for various structures with predesigned SRR as shown in Table 1.

\section{Analysis}

Effects of material properties of shield on output parameters of SRR structure were analyzed. It was observed that resonant frequency remained almost unaffected when shield material was changed. Maximum variation recorded in resonant frequency was less than 1 percent which shows independence of this parameter of shield material and dependence entirely upon dimensions of SRR structure. However, $Q$ factor was found considerably affected around 65 percent with change in shield material. Regression analysis showed heavy dependence of this factor on material properties. Highest value of $Q$ factor for SRR structure was found with AL shield, whereas it exhibited lowest value for structure with SN shield. Analysis of $Q$ factor pertaining to SRR structures of various shield materials along with study of regression equations for the same parameter revealed that increase in relative permeability had adverse effect on this parameter although mass density and bulk conductivity have similar but less significant effects.

Dependence of output parameters on variation in height and thickness of shield made of different materials was also analyzed. Inner radius of shield was kept constant to have systematic insight into output variations related to shield dimensions. Relatively larger variation (around 10 percent) was noted in resonant frequency for various geometries of SRR structure. This was expected as resonant frequency depends on shield dimensions as well. For $Q$ factor, it increased to around 70 percent. It was also observed that higher values of $Q$ factor were obtained for shield of less thickness while lower values were noted for structure with thicker shield. Regression equations showed heavy reliance of $Q$ factor on shield dimensions, whereas resonant frequency was found less affected due to dimensional variations. An increase of around 23 percent in $Q$ factor was noted against previous analysis.

Finally, inner radius of shield was also varied along with height and thickness of shield. For resonant frequency maximum variation was around 20 percent, whereas around 75 percent variation was observed in $Q$ factor for various geometries. It was noted that in each case maximum value of both resonant frequency and $Q$ factor was achieved for the same shield dimensions. However, lowest values were obtained for different shield dimensions. Regression equations showed heavy reliance of $Q$ factor on shield dimensions, whereas resonant frequency was found less effected by dimensional variations. An overall increase of around 26 percent in $Q$ factor was noted against first analysis.

In all cases, SRR structure with $\mathrm{AL}$ shield provided highest value for $Q$ factor as compared to its counterparts. Structures with BR, SS, and SN shields produced comparable results. However, structure with SN shield produced poor results. Main reason lies in relative permeability of material. Higher permeability material stores higher amount of energy, thereby absorbing energy from surrounding. As a result the amount of available energy around SRR reduces resulting in low $Q$ factor. Analysis suggests that use of material for shield with high permeability is not recommended.

Analysis presented in this work was performed with a view to develop an optimized SRR device/structure. Optimized device can sense small variation in composition of MUT. This information is gathered in the form of measured resonant frequency and $Q$ factor. Sensing very small changes is vital in high resolution compositional analysis of dielectric materials in mixture/composite.

\section{Conclusion}

Designing of appropriate shield around resonator ensures stability and enhancement in output parameters of SRR structure. This work presents an analysis of factors affecting these parameters. Dependence of these parameters on shield parameters was shown through regression equations.

While analyzing dependence over properties of shield material, it was observed that resonant frequency remained independent of shield material. Maximum variation in this parameter for SRR shield made of different material was 0.039 percent. However, $Q$ factor was considerably affected with change in shield material. Variation up to 64.83 percent was observed for shields of different materials. Highest $Q$ factor was noted for AL shield while it was lowest for CI shield. Regression equations provided dependence of output parameters over shield material properties.

Study for height and thickness of shield showed that resonant frequency varied least for $\mathrm{AL}$ shields of different dimensions, that is, $0.1757 \mathrm{GHz}$, whereas it varied maximum for BR shields, that is, $0.1997 \mathrm{GHz}$. Maximum and minimum variation in $Q$ factor was noted as 791.69 and 393.56 for $\mathrm{AL}$ and CI shields of different dimensions, respectively. Highest $Q$ factor, that is, 3115.55, was observed for AL shield while the lowest, that is, 836.7, was noted for CI shield. Regression equations provided quantified dependence of output parameters over shield dimensions.

When shield radius was included in study, it was observed that minimum variation in resonant frequency, that is, $0.2862 \mathrm{GHz}$, was noted for AL, BR, and SN shields of different dimensions. SS shield showed $0.2861 \mathrm{GHz}$ variation. While maximum variation, that is, $0.4238 \mathrm{GHz}$, was noted for CI shield. Maximum variation in $Q$ factor, that is, 1096.15 , was noted for AL shield of different dimensions while lowest variation, that is, 558.3, was noted for CI shields. Highest Q factor, that is, 3226.05, was observed for AL shield while the lowest, that is, 830.21, was noted for CI shield. Regression equations quantified dependence in this case also.

It was also shown that shield enclosing a predesigned SRR with appropriate dimensions can result in optimized output parameters. Moreover, SRR structure can be designed for desired value of $Q$ factor with corresponding resonant frequency with the help of data obtained for analysis.

Optimized SRR device/structure could be used to improve performance of devices where such structure is used. For instance high selectivity can be achieved in filters and tuned amplifiers. Regression equations developed in this work provide an easy and effective tool to judge performance of device. 


\section{Conflict of Interests}

The authors declare that there is no conflict of interests regarding the publication of this paper.

\section{References}

[1] W. N. Hardy and L. A. Whitehead, "Split ring resonator for use in magnetic resonance from $200-2000 \mathrm{MHz}$, Review of Scientific Instruments, vol. 52, no. 2, pp. 213-216, 1981.

[2] W. Froncisz and J. S. Hyde, "The loop-gap resonator: a new microwave lumped circuit ESR sample structure," Journal of Magnetic Resonance, vol. 47, no. 3, pp. 515-521, 1982.

[3] M. Mehdizadeh, T. K. Ishii, J. S. Hyde, and W. Froncisz, "Loopgap resonator: a lumped mode microwave resonant structure," IEEE Transactions on Microwave Theory and Techniques, vol. 31, no. 12, pp. 1059-1064, 1983.

[4] M. Mehdizadeh and T. K. Ishii, "Electromagnetic field analysis and calculation of the resonance characteristics of the loopgap resonator," IEEE Transactions on Microwave Theory and Techniques, vol. 37, no. 7, pp. 1113-1118, 1992.

[5] J. S. Hong and M. J. Lancaster, "Theory and experiment of novel microstrip slow-wave open-loop resonator filters," IEEE Transactions on Microwave Theory and Techniques, vol. 45, no. 12, pp. 2358-2365, 1997.

[6] A. Masood, O. Castell, D. A. Barrow, C. Allender, and A. Porch, "Split ring resonator technique for compositional analysis of solvents in microcapillary systems," in Proceedings of the 12th International Conference on Miniaturized Systems for Chemistry and Life Sciences (MicroTAS '08), pp. 1636-1638, San Diego, Calif, USA, October 2008.

[7] D. J. Rowe, S. Al-Malki, A. A. Abduljabar, A. Porch, D. A. Barrow, and C. J. Allender, "Improved split-ring resonator for microfluidic sensing," IEEE Transactions on Microwave Theory and Techniques, vol. 62, no. 3, pp. 689-699, 2014.

[8] L. F. Chen, C. K. Ong, C. P. Neo, V. V. Varadan, and V. K. Varadan, Microwave Electronics: Measurement and Materials Characterization, John Wiley \& Sons, 2004.

[9] H. S. Nalwa, Ed., Handbook of Low and High Dielectric Constant Materials and Their Applications, Two-Volume Set, Academic Press, 1999.

[10] S. S. Eaton and G. R. Eaton, Biological Magnetic Resonance: Biomedical EPR, Part B: Methodology, Instrumentation, and Dynamics, vol. 24, Plenum Press, New York, NY, USA, 2005.

[11] O. Sydoruk, E. Tatartschuk, E. Shamonina, and L. Solymar, "Analytical formulation for the resonant frequency of split rings," Journal of Applied Physics, vol. 105, no. 1, Article ID 014903, 2009.

[12] G. A. Rinard, R. W. Quine, S. S. Eaton, and G. R. Eaton, "Microwave coupling structures for spectroscopy," Journal of Magnetic Resonance Series A, vol. 105, no. 2, pp. 137-144, 1993.

[13] T. Ejaz, H. U. Rahman, S. A. A. Shah, and T. Zaidi, "A comparative analysis of split-ring resonator models," in Proceedings of the 4th International Conference on Informatics, Electronics \& Vision (ICIEV '15), p. 61, Fukuoka, Japan, June 2015.

[14] Ansoft HFSS, 3-D Electromagnetic Simulation Software, Ansoft Corporation, Pittsburgh, Pa, USA, 2009.

[15] T. Ejaz, S. A. A. Shah, H. U. Rahman, and T. Zaidi, "Improved shield design for split-ring resonator," in Proceedings of the $3 \mathrm{rd}$ International Conference on Technological Advances in Electrical, Electronics and Computer Engineering (TAEECE '15), pp. 207211, IEEE, Beirut, Lebanon, April-May 2015.
[16] T. Ejaz, H. U. Rahman, T. Zaidi, T. Tauqeer, and S. A. Shah, "Analysis, simulation, and experimental verification of splitring resonator," Microwave and Optical Technology Letters, vol. 57, no. 10, pp. 2358-2363, 2015.

[17] C. Saha and J. Y. Siddiqui, "A comparative analyis for split ring resonators of different geometrical shapes," in Proceedings of the IEEE Applied Electromagnetics Conference (AEMC '11), Kolkata, India, December 2011.

[18] N. Abutahoun and M. Ouda, "A crescent shaped split ring resonator to form a new metamaterial," The International Journal of Engineering and Technology, vol. 2, no. 10, pp. 809813, 2012.

[19] S. Ramo, J. R. Whinnery, and T. Van Duzer, Fields and Waves in Communication Electronics, John Wiley \& Sons, 2008.

[20] A. N. A. Jabita, Design of singly split single ring resonator for measurement of dielectric constant of materials using resonant method [M.S. thesis], University of Gavle, Gävle, Sweden, 2013.

[21] M. Proust and JMP, Design of Experiments Guide, SAS Institute, Cary, NC, USA, 2nd edition, 2009.

[22] A. G. Bluman, Elementary Statistics: A Step By Step Approach, A Brief Version, no. 519.5 B585E, McGraw-Hill, New York, NY, USA, 2008.

[23] Minitab, MINITAB Statistical Software. Minitab Release, 17, Minitab, 2014. 


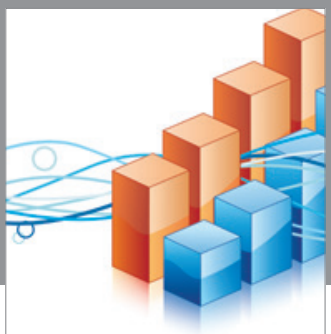

Advances in

Operations Research

vatem alat4

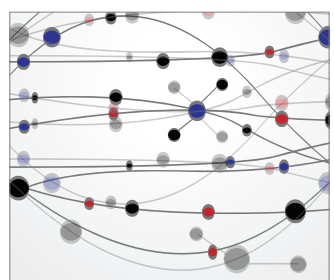

\section{The Scientific} World Journal
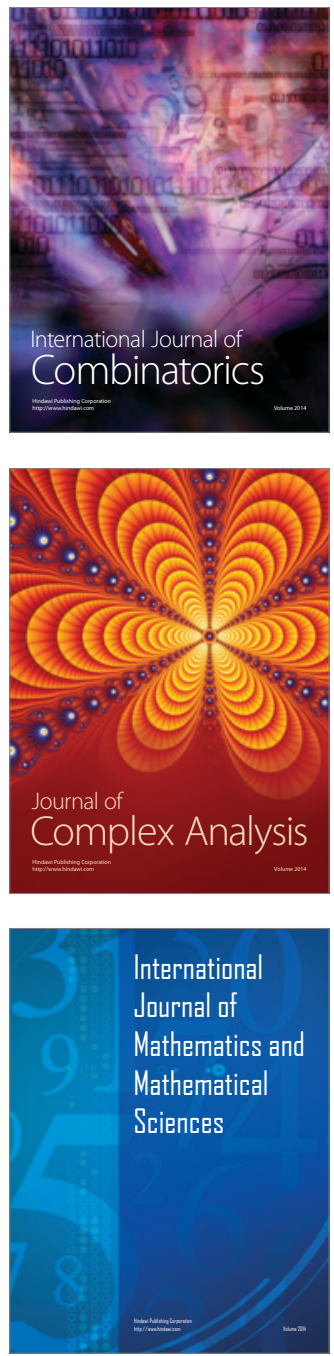
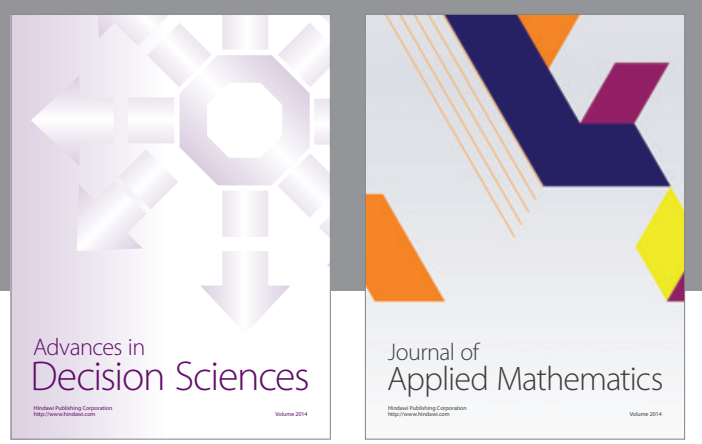

Algebra

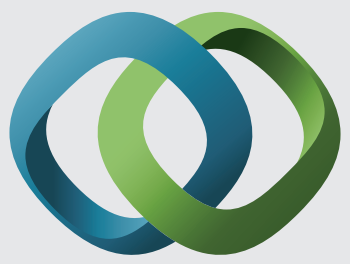

\section{Hindawi}

Submit your manuscripts at

http://www.hindawi.com
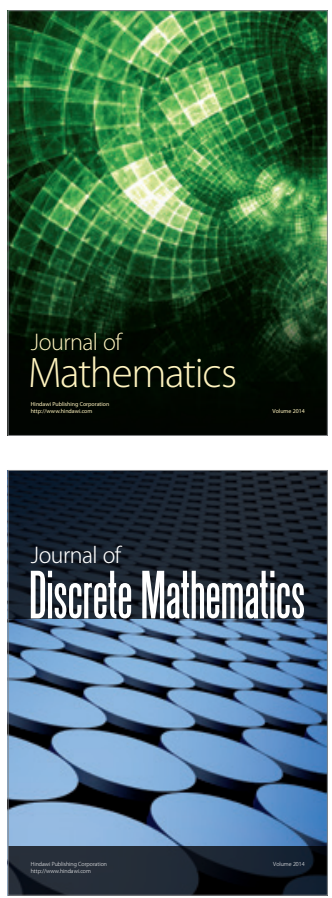

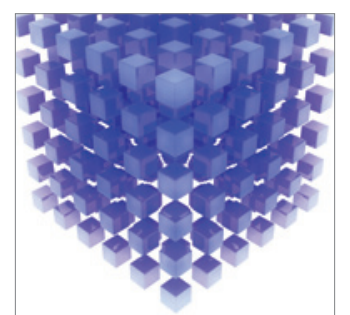

Mathematical Problems in Engineering
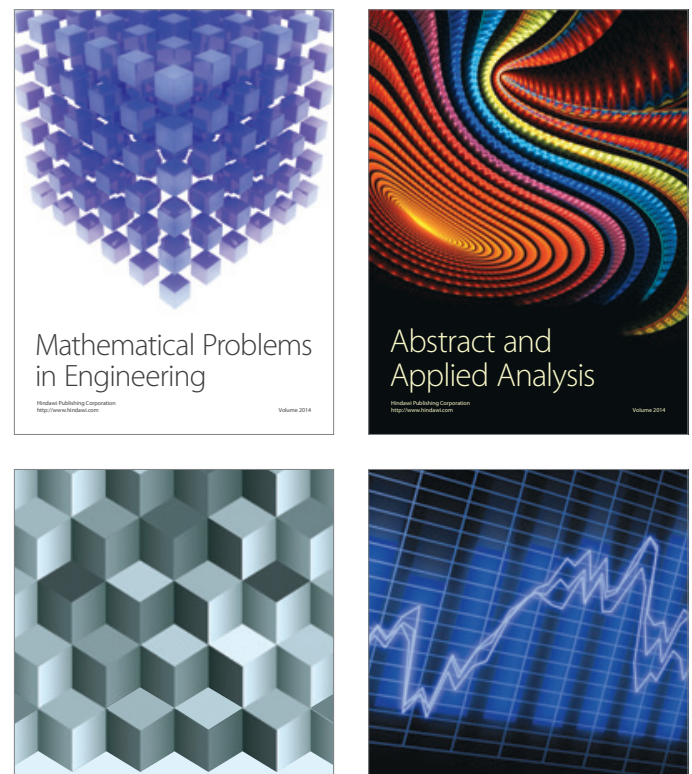

Journal of

Function Spaces

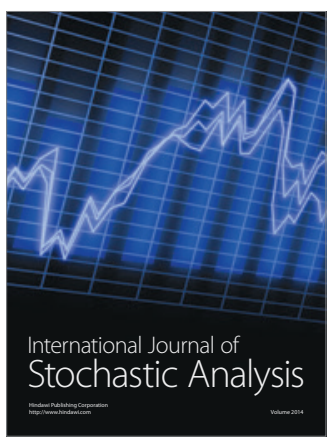

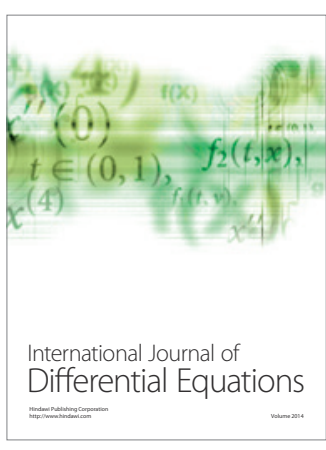
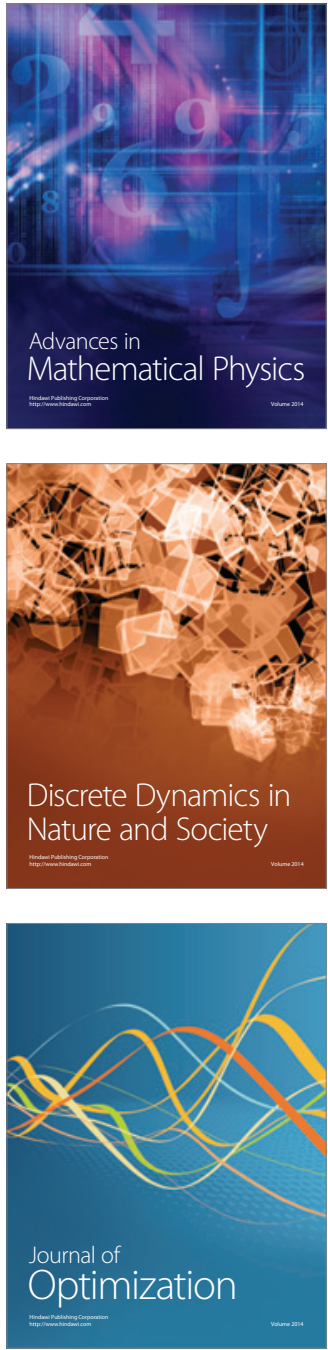